\title{
SPACE VECTOR MODULATION IN MULTILEVEL INVERTERS OF THE SERVO DRIVES OF THE TRAJECTORY MEASUREMENTS TELESCOPES
}

\author{
V. S. Tomasov ${ }^{1}$, A. A. UsoltseV ${ }^{1}$, D. A. Vertegel ${ }^{1}$, R. StRZelecki ${ }^{2}$ \\ ${ }^{1}$ ITMO University, 197101, St. Petersburg, Russia \\ E-mail: tomasov@ets.ifmo.ru \\ ${ }^{2}$ Electrotechnical Institute in Warsaw, Gdynia, Poland
}

\begin{abstract}
Using the MatLab/Simulink mathematical model of a three-phase three-level voltage inverter, the influence of the space-vector modulation (SVM) algorithm on the pulsations of the current (torque) of an AC motor in the range of low rotation speeds is considered. It is shown that the SVM of the second kind does not provide a pulsations level comparable to the pulsations of a sinusoidal pulse-width modulation (SPWM), both in the static mode of the drive operation and in transient modes. In such case, the current pulsations cannot be reduced by changing the modulation algorithm, which almost excludes the possibility of using such transducers in high-quality adjustable instrumental AC electric drives. At the same time, SVM of the first kind can be considered as an alternative to SPWM, as it allows to reduce the current pulsations in the largest part of the control range to a comparable level, and in the last quarter of the control range to values significantly lower than with the SPWM. The asymmetry of the inverter characteristics with the SVM is noted for different directions of the modulation vector rotation.
\end{abstract}

Keywords: three-level voltage inverter, space-vector modulation, sinusoidal pulsewidth modulation, modulation algorithms, current pulsations, instrumental electric drive

Introduction. The creation of the optical telescopes of trajectory measurements (TTM) and their control systems for solving problems of near-Earth space monitoring is one of the most difficult tasks of modern precision instrumentation. The complexity of this task lies in the fact that the TTM electromechanical control systems are instrumental servo drives, which solve the problem of superposing the optical axis of the telescope with the sight line of the observed moving object or the problem of space stabilization of the telescope field of view and the optical image in its focal plane. They should provide a unique high quality guidance: at the level of ones of angular seconds at speeds of rotation from ones of angular seconds per second to tens of degrees per second [1, 2].

The use of a direct electric drives based on torque motors, high-precision optical angle sensors, and high-efficiency power transducers makes possible to create TTM guidance systems that meet modern requirements of the world instrument producing and provide the required accuracy of guidance.

With that, the servo drives of the TTM should be designed taking into account the elastic linkage, friction, disturbances actions from the bearings and cable transition, and the discreteness of electromagnetic processes, what considerably complicate the control processes [3].

The power transducers of the instrumental servo drives of the TTM, which are developed at the ITMO University, are the energy-efficient voltage inverters with various modulation algorithms [4].

It is known that voltage inverters, being pulse regulators, form a load current that contains, in addition to the smooth component high-frequency pulsations. These pulsations inevitably lead to undesirable pulsations of the motor torque in precision servo drives [4].

There are two obvious approaches to solving the problem of reducing the pulsations of current and torque: 1) increasing the number of possible states of the output voltage of the inverter by increasing the number of switching components; 2) improving the states changing algorithm of the 
invertor. The first one leads to the creation of multi-level inverters with various structures (capacitorclamped inverters, diode-clamped inverters, cascaded inverters and cascaded hybrid inverter) combining two types of modulation: amplitude and pulse-width (PWM) [5]. The second approach provides the development and the improvement of pulse-width modulation algorithms. In the last two decades, much attention has been paid to studying the space-vector PWM (SVM) algorithms, characterized by a high level of the fundamental harmonic of the output voltage, a low harmonic factor of the current in the load, less switching loses, and good conditioning with microprocessor control systems. Certain successes have been achieved by developing algorithms that generate additional virtual base vectors via cyclic switching $[6,7]$. There are researches of improving the algorithms which use additional states of switches corresponded to real base vectors [8,9], as well as algorithms optimized using neural network controllers [10,11].

However, SVM also includes additional sequences of forming the base vectors within the cycle, which obviously must lead to different pulsations of the flux-linkage (current) vector. Moreover, within the switching cycle, the durations of the calculated intervals retain their values, what should also affect the pulsations, as this corresponds to the sampling of the modulation signal. This paper is devoted to the investigation of the influence of these factors on the current pulsations in load of the voltage inverters.

Algorithms of space-vector modulation. In the case of SVM, the intermediate states of the output voltage of the inverter and the modulation signal are represented by space vectors. The possible inverter states conform to a finite set of vectors called base vectors. For the most widespread three-phase inverters, the ends of the base vectors split the plane into equilateral triangular segments and sectors located between the phase axes (Fig. 1).

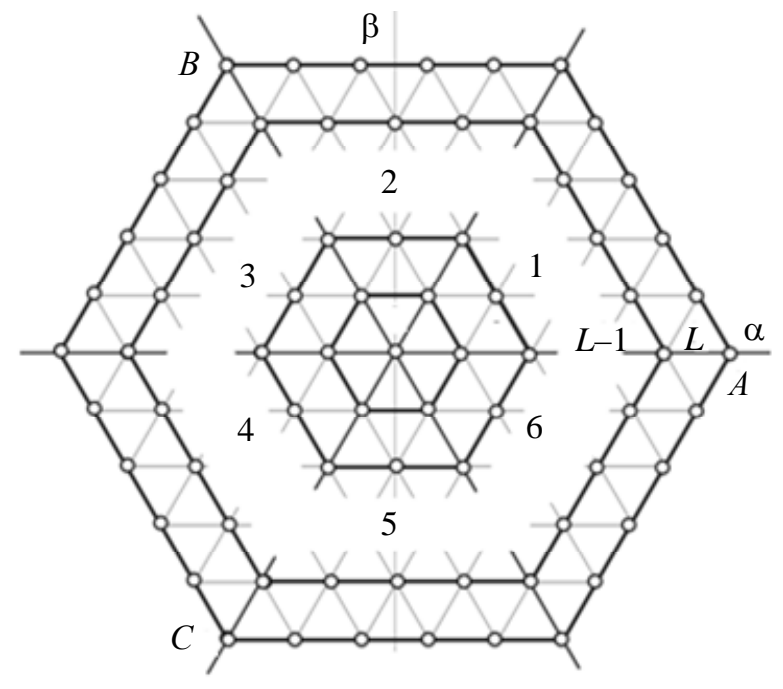

Fig. 1

The principle of SVM consists in sequential forming the three base vectors nearest to the end of the modulation vector $\mathbf{U}^{*}=U^{*} e^{j \vartheta^{*}}$. What is more, the forming duration of these vectors is determined by the values of the skew-angle projections of the end of the vector $\mathbf{U}^{*}$ on the sides of the triangle of the corresponding segment. In sum the three durations form the modulation period $T_{c}=$ const . The microcontroller function is to determine the current segment and the forming durations of the base vectors.

By the arrangement of the vertices relative to the axis of the phase $A$, two types of the basic vectors segments are formed. Denote them as A- and V-segments due to similarity (Fig. 2). 
a)

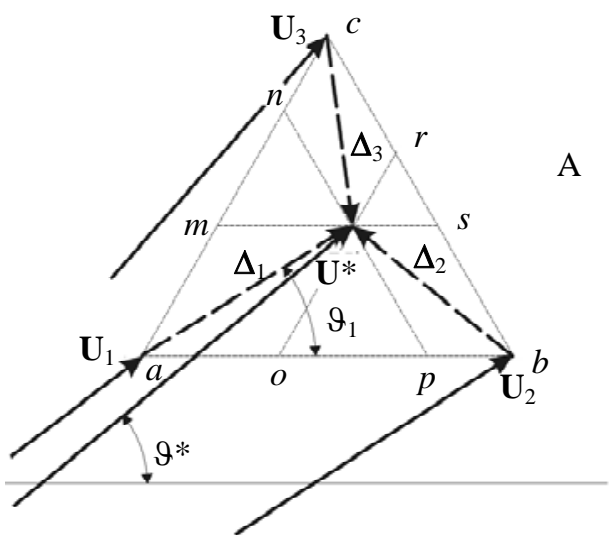

b)

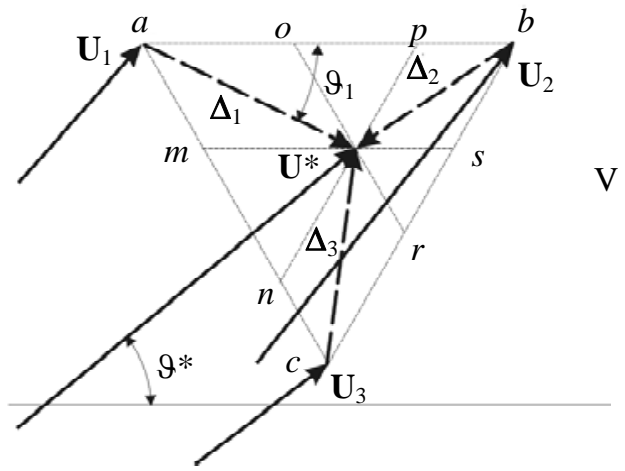

Fig. 2

Durations $t_{1}, t_{2}$ and $t_{3}$ corresponding to the forming intervals of the vectors $\mathbf{U}_{1}, \mathbf{U}_{2}$ and $\mathbf{U}_{3}$ can be calculated using an obvious formula $\mathbf{U}^{*}=\mathbf{U}_{1}+\boldsymbol{\Delta}_{1}$, where

$$
\begin{aligned}
\boldsymbol{\Delta}_{1}=\mathbf{a m} & +\mathbf{a o}=\left(\mathbf{U}_{3}-\mathbf{U}_{1}\right) t_{1} / T_{C}+\left(\mathbf{U}_{2}-\mathbf{U}_{1}\right) t_{2} / T_{C}= \\
& =\left[\mathbf{U}_{3} t_{1}+\mathbf{U}_{2} t_{2}-\mathbf{U}_{1}\left(t_{1}+t_{2}\right)\right] / T_{C},
\end{aligned}
$$

along with geometric constructions

$$
\left.\begin{array}{l}
a m=b s=\frac{t_{1}}{T_{c}}=\tau_{1}=\frac{2 \Delta_{1} \sin \vartheta_{1}}{\sqrt{3}} ; \\
a o=c r=\frac{t_{2}}{T_{c}}=\tau_{2}=\Delta_{1} \cos \vartheta_{1}-a m \cdot \sin 30^{\circ}=\Delta_{1} \cos \vartheta_{1}-\frac{t_{1}}{2 T_{c}}, \\
b p=c n=\frac{t_{3}}{T_{c}}=\tau_{3}=1-\tau_{1}-\tau_{2}=1-\frac{2 \Delta_{1}}{\sqrt{3}} \sin \left(\vartheta_{1}+\frac{\pi}{3}\right) .
\end{array}\right\}
$$

These equations also allow to define vectors $\boldsymbol{\Delta}_{2}=\mathbf{b p}+\mathbf{b s}$ and $\boldsymbol{\Delta}_{3}=\mathbf{c n}+\mathbf{c r}$. In this case, the durations $\tau_{1} \equiv \mathbf{U}_{1}, \tau_{2} \equiv \mathbf{U}_{2}$ and $\tau_{3} \equiv \mathbf{U}_{3}$ are the same regardless of what difference $\boldsymbol{\Delta}$ is used to calculate the vector $\mathbf{U}^{*}=\mathbf{U}_{1}+\boldsymbol{\Delta}_{1}=\mathbf{U}_{2}+\boldsymbol{\Delta}_{2}=\mathbf{U}_{3}+\boldsymbol{\Delta}_{3}$. Usually, the real number axis $\alpha$ is superposed with the winding axis of phase $A$. To determine the durations $\tau_{1}, \tau_{2}$, and $\tau_{3}$, equations (2) are used, regardless of which sector of the SBV (surface of the base vectors) the vector $\mathbf{U}^{*}$ is in. To do this, its position is reduced to the first sector by a simple transformation $\hat{\mathbf{U}}^{*}=\left|\mathbf{U}^{*}\right| e^{j \cdot \operatorname{rem}\left(39^{*} / \pi\right)}$, where $\operatorname{rem}(a / b)$ is the function that returns the remainder after division of $a$ by $b$. This sector is called basic sector.

Equations (1), (2) used to calculate the durations of intervals in the A-segment (Fig. 2, b) will be true for the $\mathrm{V}$-segment if you save the coordinates system and the notation for it. However, the angle $\vartheta_{1}$ will be negative and the value $\sin \vartheta_{1}$ should be calculated in absolute value. 
Usually, to form the time intervals a two-sided symmetrical PWM of the second kind is used (Fig. 3). In this case, the durations $\tau_{1}, \tau_{2}$, and $\tau_{3}$ are determined at the beginning of the modulation period $T_{C}$. With that, the halves of two intervals are formed at the beginning and the end of the period. Such a modulation algorithm provides the best harmonic composition of the load voltage and current with the least number of commutations. However, the forming sequence of these intervals may be different. Along with this, the spectrum of the load currents will be different too.

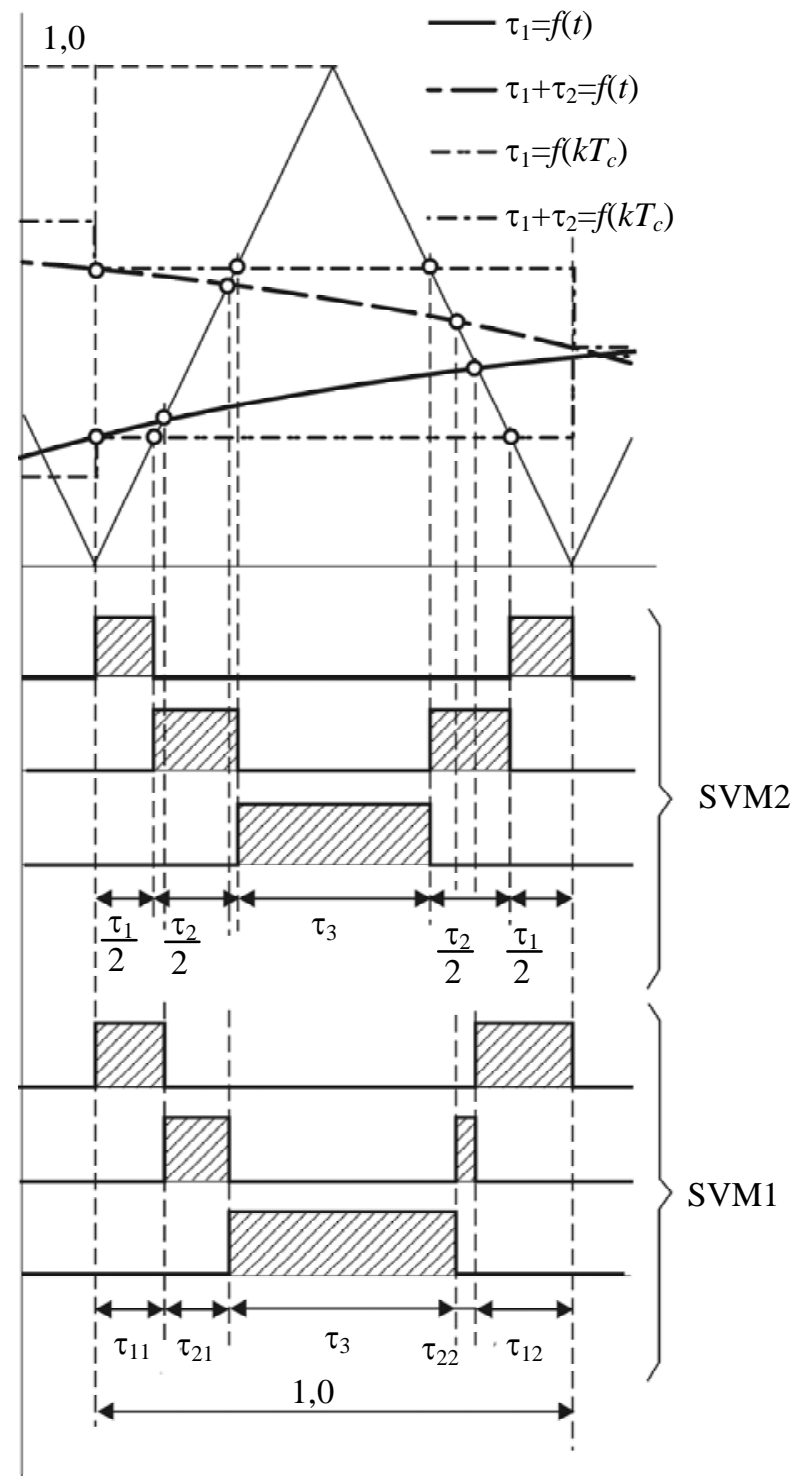

Fig. 3

The questions related to the effects of the modulation algorithm on the load current pulsations using the example of a three-level voltage inverter considered below. Fig. 4 shows the base sector of such an inverter. There are three-digit numbers denoting the normalized phase voltages standing for the vertices of the segments which conditional numbers are indicated in the circles.

Basic sector could be splitted into three modulation zones. The first zone includes a linear modulation area of the segment I corresponding to the modulation level $0 \leq\left|\mathbf{U}^{*}\right|<\sqrt{3} / 2 \approx 0.866$ (Fig. 4). In this zone vectors with zero and single values of the phase voltage are formed, what corresponds for a linear two-level inverter. The second zone includes segments II, III, and IV at the modulation level $1.0 \leq\left|\mathbf{U}^{*}\right|<\sqrt{3} \approx 1.732$. Each of three levels of the normalized phase voltages $-0,1$, and 2, are used while forming the base vectors, but a zero vector is not used. The third modulation 
zone, called the transition zone, corresponds to $\sqrt{3} / 2 \leq\left|\mathbf{U}^{*}\right|<1.0$ (in Fig. 4 it is shaded). In this field, the modulation is carried out in two segments (I and III), which belongs to different types. Just as in the second zone, all three levels of the normalized phase voltages are used here, but unlike to the second zone, a zero vector is used.

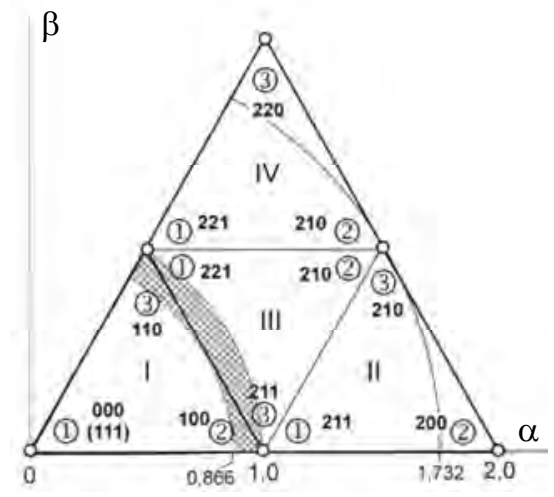

Fig. 4

We introduce the definition of the modulation coefficient $k_{m}$ as the ratio of the absolute value of the modulation signal $\left|\mathbf{U}^{*}\right|$ to the voltage of the first level. In this case, range of the linear voltage regulation is obtained as $0 \leq k_{m} \leq \sqrt{3} \approx 1.732$.

A possible variants of the algorithms (sequences - Sq) of formatting the base vectors in the linear two-level modulation zone are considered below. There are six such variants (Fig. 5). The vector 000 or the vector 111 could be used as the zero base vector. In the first case, there is no commutations in phase $C$ of the inverter, in the second case there is no commutations in phase $A$.

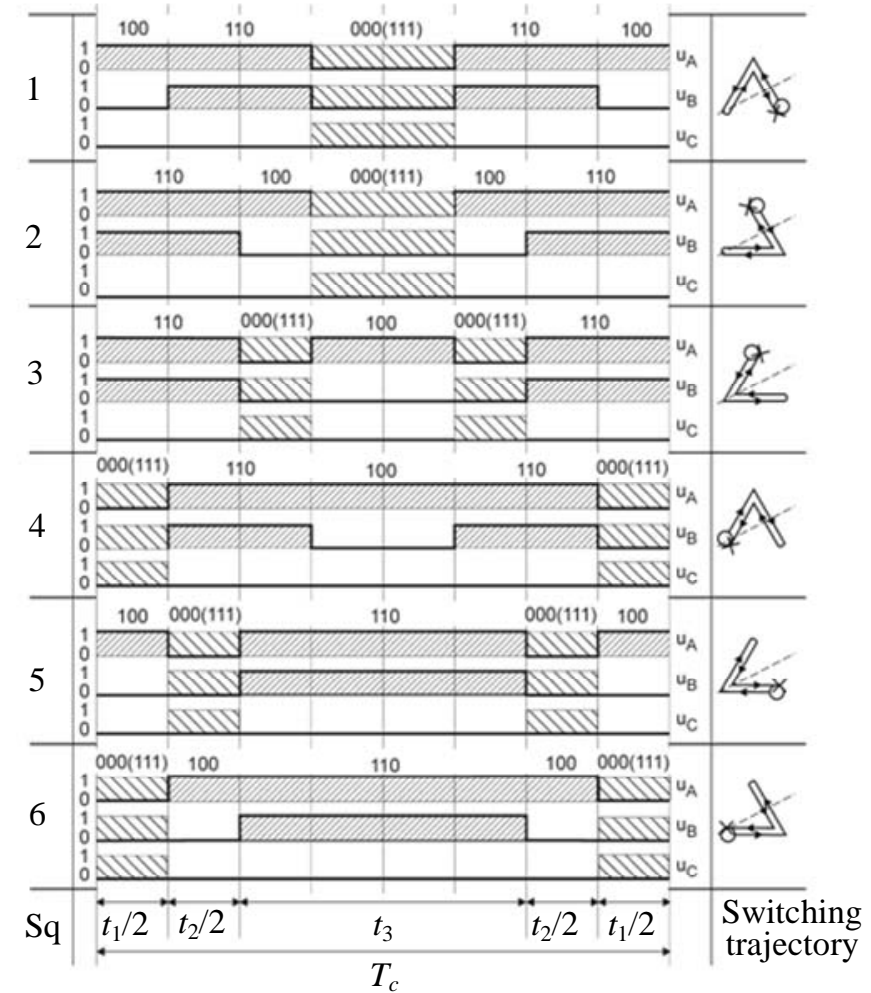

Fig. 5

Changing the algorithm of the base vectors formatting changes the trajectory of their switching within the segment. This leads to changes in the shape of the current vector hodograph and, consequently, to changes in the magnitude pulsations. 
Moreover, the voltage and the current hodographs change when the direction of the modulation vector $\mathbf{U}^{*}$ rotation changes. For the instrumental drives, it is important to maintain the characteristics symmetry of the transducer in the reverse, therefore, it is required to change the switching trajectories of the base vectors to mirror-symmetrical related to the bisector of the central angle of the basic sector (it is shown by dashed lines in Fig. 5). This is because the current vector hodograph is a response to the influence of the voltage vector in the target direction. Therefore, the sequence formation of the base vectors in the segments has to be the same towards the direction of rotation. For example, if at some random initial position of the vector $\mathbf{U}^{*}$ in the segment I (Fig. 4) for motion in the positive direction the vector 3 , which is the last in the direction of rotation, is formed the first in the algorithm 3-2-1-2-3, then, to move in the opposite direction, the extreme vector 2 should be formed the first, and the algorithm should be 2-3-1-3-2. This condition is provided by changing of the algorithms in pairs that have the property of mirror symmetry of the switch trajectories: $1-2,3-5$ and 4-6 (Fig. 5).

The SVM asymmetry considered in the example of the segment I is also inherent in processes in all other voltage inverter segments with any number of the modulation levels.

A feature of the SVM consists in abrupt changes of the switching algorithm in the transitions of the modulation vector from one segment to another as the result of the rotation, as well as in the transitions from one modulation zone to another as the result of the absolute value of $\mathbf{U}^{*}$ changing.

The tasks of the modeling and evaluating of the transformation quality. Rotation of the modulation vector with a constant absolute value within the SBV segment causes a monotonous changing the formation durations $\tau_{1}$ and $\tau_{2}$ of the base vectors (Fig. 6). Usually, for the SVM, the durations are calculated at the beginning of the modulation period, which corresponds to modulation of the second kind - SVM-2. In this case, symmetric commutation functions are obtained, but information about changing of the modulation signal within the modulation period is lost. Symmetry improves the harmonic composition of the voltage and the current in the load of the inverter, but slows down the response to the changing in the modulation signal. In fact, any type of the PWM of the second kind, including SVM-2, is a discretization of the modulation signal. This is not significant for transducers used as unregulated power supplies or regulated in a small range, which dynamics behavior is not imposed high requirements. For the frequency converters of the AC instrumental drives the rising action is an important parameter. For that reason, the problem of choosing the type of modulation is always relevant. If the processor power allows calculating of $\tau_{1}$ and $\tau_{2}$ within the modulation period, then the modulation of the first kind (Fig. 3) can be used in the voltage inverter, what should decrease the pulsations of the load current.

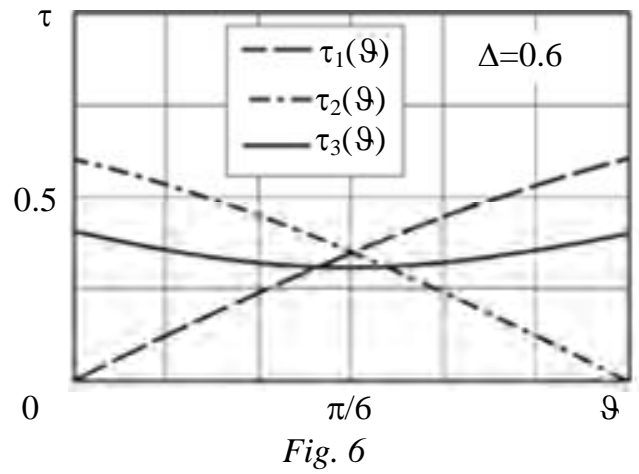

In this article, a three-level inverter is chosen as the object of the investigation, since the influence of the modulation algorithm in the different modes is the most clearly manifested in it. At the same time, obtained results can be extended to the inverters with a larger number of levels, as well as to the two-level inverters. In addition, with deep regulation, what is necessary to create infra-low speeds of the instrumental drive, regardless of the total number of the inverter levels, the current 
formation takes place in two or three-level operation mode. With that, the EMF of the motor rotation is practically equal to zero, and for the inverter it is a passive resistive-inductive load. Therefore, a symmetrical RL-circuit was used as the load.

To exclude the influence on the result of other factors, the study was realized in the MatLab/Simulink environment on the model of an ideal three-level inverter (Fig. 7). Each phase of this transducer is a group of five ideal switches $\left(S_{A 1} \ldots S_{A 5}\right)$ with a switching algorithm that corresponds to the next condition at every time moment:

$$
\begin{aligned}
& s_{A 1}+s_{A 2}+s_{A 3}+s_{A 4}+s_{A 5}=1 ; \\
& s_{B 1}+s_{B 2}+s_{B 3}+s_{B 4}+s_{B 5}=1 ; \\
& s_{C 1}+s_{C 2}+s_{C 3}+s_{C 4}+s_{C 5}=1,
\end{aligned}
$$

where $s_{A 1} \ldots s_{A 5} ; s_{B 1} \ldots s_{B 5} ; s_{C 1} \ldots s_{C 5}$ are the switching functions of the switches that take the value of one in the closed state and the value of zero in the open state.

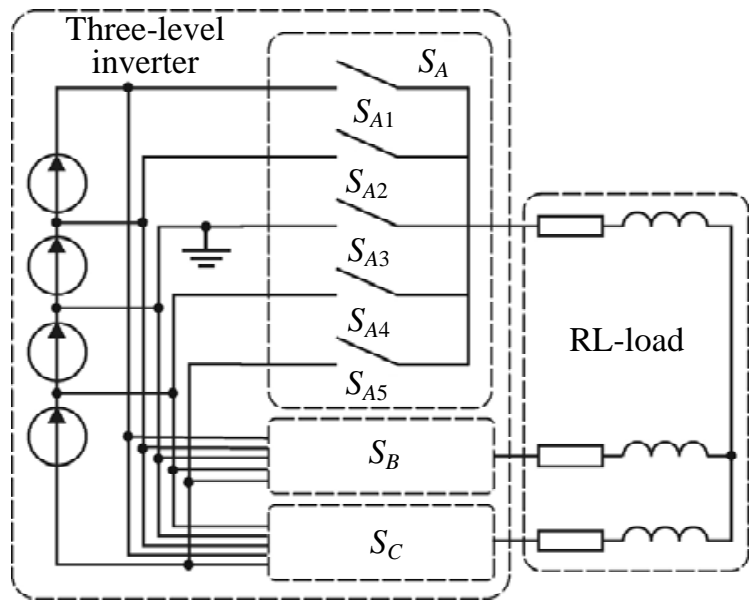

Fig. 7

The frequency of the fundamental harmonic $f_{1}$ was used in the model as the base value, in relation to which the modulation frequencies $f_{c}$ multiplied of six and the electromagnetic time constant of the RL-load $\tau_{R L}=R / L=1 /\left(5 f_{1}\right)$ were used.

Usually the quality of the transducer is estimated by the total harmonic distortion coefficient of the phase current waveform

$$
K_{g}=\frac{\sqrt{\sum_{k=2}^{\infty} I_{k}^{2}}}{I_{1}} .
$$

However, the task of the inverter of the AC drive is to form a circular hodograph of the current vector, so the quality of the transducer should be estimated from the pulsations of the current module $|\mathbf{I}|$. This can be done using the coefficient of variation

$$
K_{v}=\frac{\sqrt{\frac{1}{T_{1}} \int_{0}^{T_{1}}(|\mathbf{I}|(t)-|\overline{\mathbf{I}}|)^{2} d t}}{|\overline{\mathbf{I}}|},
$$

where $|\overline{\mathbf{I}}|=\frac{1}{T_{1}} \int_{0}^{T_{1}}|\mathbf{I}|(t) d t$ is the average value of the absolute value for the period of the fundamental harmonic $T_{1}=1 / f_{1}$. 
Estimation of the stator flux (current) deviation can be made by integrating the error during the modulation period [12]. However, such estimation is not related to the power of the higher harmonics and therefore inadequately reflects their influence on the electromagnetic torque of the machine.

One can show that for an equal spectrum of the higher harmonics of the phase current and the absolute value of the current vector between $K_{g}$ and $K_{v}$, there is a linear relationship $K_{g} / K_{v}=\sqrt{2}$.

However, the phase current is the projection of the current vector onto the phase axis, and if the current absolute value contains higher harmonics, that is

$$
|\mathbf{I}|=I_{0}+\sum I_{m k} \sin \left(k \omega t+\beta_{k}\right),
$$

then the current vector rotates with the frequency $\omega$ and equals to

$$
\mathbf{I}=\left[I_{0}+\sum I_{m k} \sin \left(k \omega t+\beta_{k}\right)\right] e^{j \omega t},
$$

and the current of phase $A$ is

$$
\begin{gathered}
\operatorname{Re}(\mathbf{I})=i_{A}(t)=\left[I_{0}+\sum I_{m k} \sin \left(k \omega t+\alpha_{k}\right)\right] \cos \omega t= \\
=I_{0} \cos \omega t+\sum \frac{I_{m k}}{2}\left\{\sin \left[(k+1) \omega t+\alpha_{k}\right]+\sin \left[(k-1) \omega t+\alpha_{k}\right]\right\} .
\end{gathered}
$$

Consequently, the spectrums of the higher harmonics of the phase current and the absolute value of the current vector are different, so the quality of the transformation should be estimated using the coefficient of variation.

Until now, the question of using SVM in an AC drive as an alternative to sinusoidal PWM (SPWM) is still open [13-17]. The characteristics of the SPWM are also investigated in this article, it allowed to compare them with the characteristics of the SVM.

Results of the investigation and conclusions. Fig. 8 shows the main results of the parallel simulation of a three-level inverter with the SPWM and the SVM for the equal average values of the absolute value of the load current vector in the static mode (Fig. 8, $a, c$ ); Fig. 8, $b, d$ shows the graph of the coefficient $K_{v}$ for the various combinations of the modulation algorithms in A- and V-segments. Fig. 9 shows the response of the current vector to a linear increasing of the absolute value of the modulation vector.
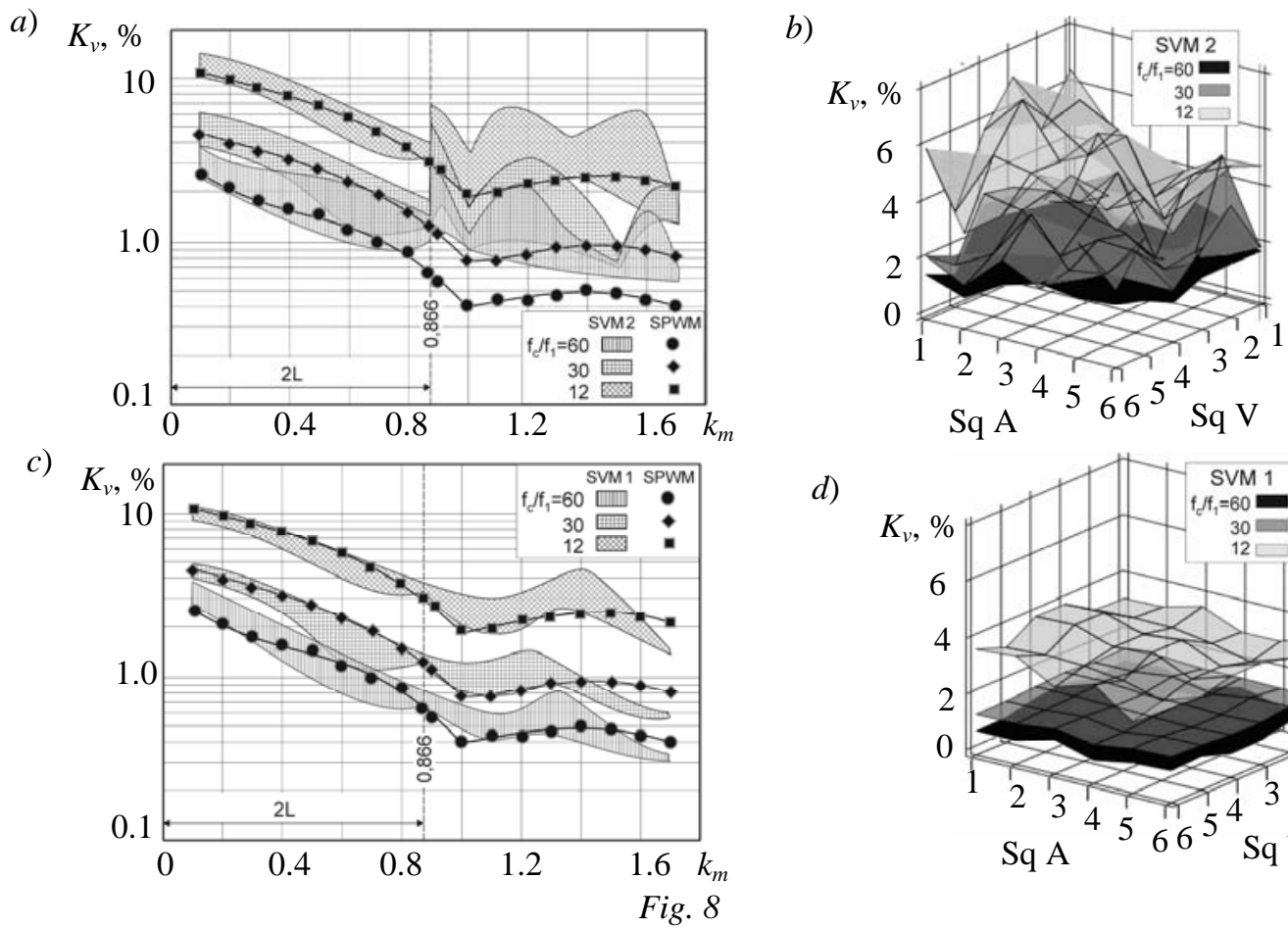

d)

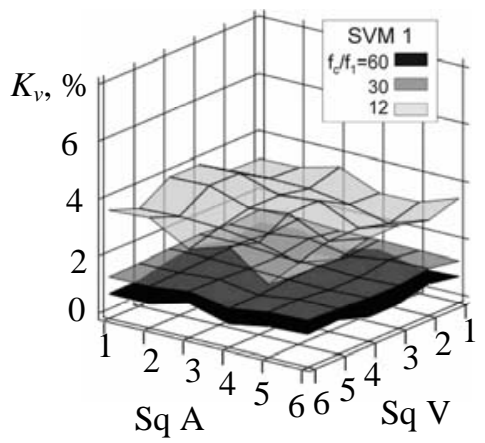



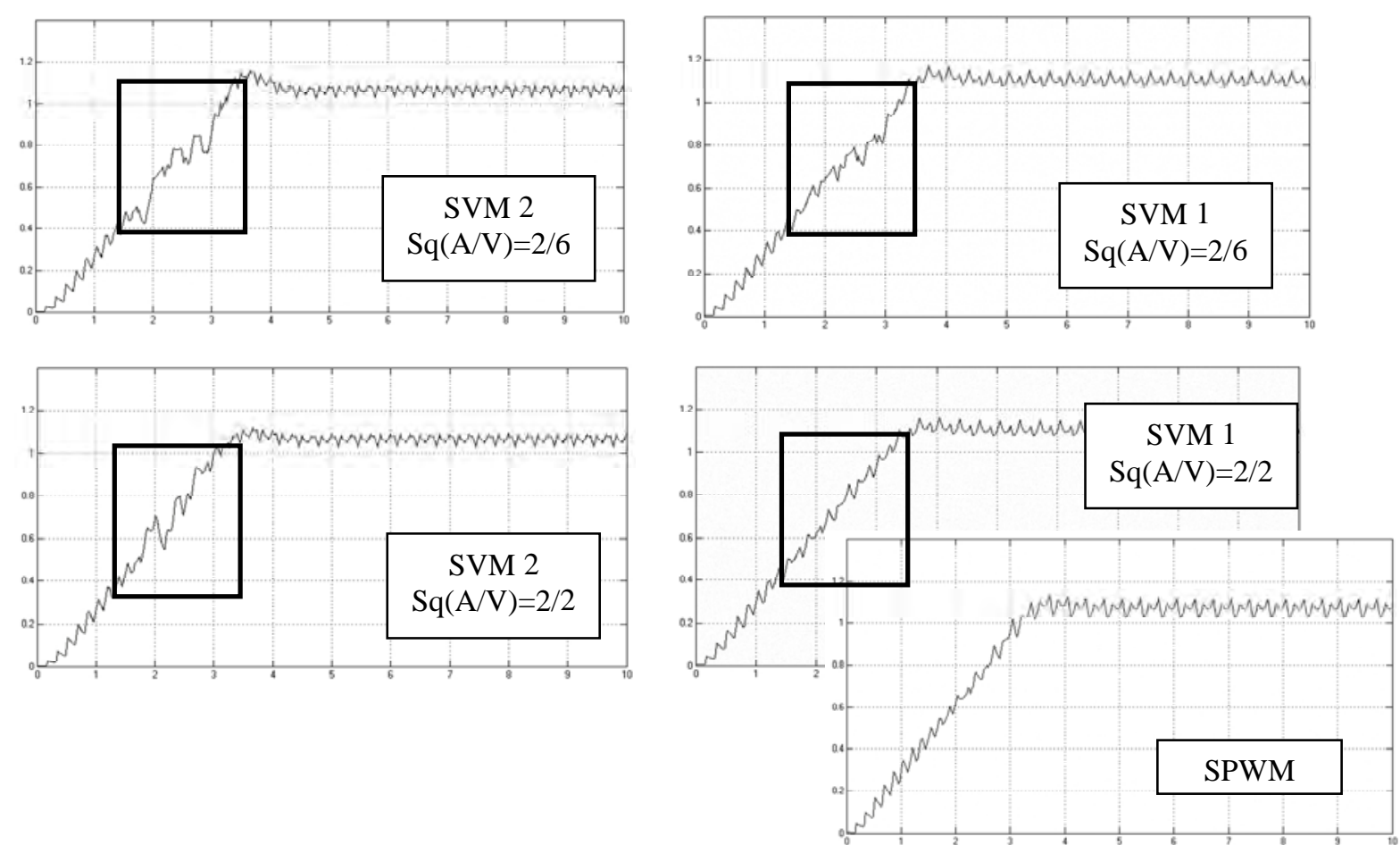

Fig. 9

Based on these results, the following conclusions can be drawn.

1. Spectral characteristics of the inverters with the SVM have abrupt disturbances associated with the modification of the modulation algorithm, when the modulation vector passes from one segment to another, from one modulation zone to another, and also with changing the direction of its rotation. Inverters with the PWM don't have this disadvantage.

2. Inverters with the SVM-2 form a current in the load with significant pulsations, what cannot be reduced by the choice of the modulation algorithm. This excludes the possibility of using such transducers in high-precision adjustable AC electric drive.

3. Using SVM-1 in a three-level inverter allows:

- to reduce the current pulsations in the load more than twice in the entire range of regulation;

— practically to eliminate the abrupt change in the current spectrum at the lower boundary of the transition zone of the modulation; algorithm;

— to reduce the current pulsations in the transition zone by choosing the optimal modulation

- to consider such a transducer as one of the possible variants of a regulated power supply for an instrumental AC drive.

4. Sinusoidal PWM has an absolute advantage in comparison with SVM-2, since it doesn't have a discontinuity of spectral characteristic. However, in the transition to three-level modulation $\left(k_{m} \geq 1.0\right.$ ), the current spectrum sharply changes. In the static mode, the current pulsations at the SPWM corresponds approximately to the lower boundary of the pulsation area of the SVM-2 in the two-level mode and significantly exceed these limits in the three-level mode, especially at the high modulation frequency.

5. Compared to the SVM-1, the sinusoidal PWM has no advantages in the two-level mode, but up to the middle of range of the three-level mode, the current pulsations with the SPWM correspond to the lower boundary of the pulsation area of the SVM-1. At the same time, in the range close to the upper limit of the modulation coefficient $\left(k_{m}>1.4\right)$, the SPWM is worse than the SVM-1 by the magnitude of the current pulsations. However, in the instrumental drive, this area usually corre- 
sponds to the motion with a high speed, where the pulsations of current and torque don't have a significant effect on the drive characteristics.

The analysis of the obtained results allows drawing a conclusion about the expediency of using the SPWM in the inverters of the instrumental drive, all other things being equal.

\section{REFERENCES}

1. Vasiliev V. N., Tomasov V. S., Shargorodsky V. D., Sadovnikov M. A. Precision electric drive systems used in high accuracy complexes of space objects watching. current statement and development prospects // Journal of Instrument Engineering. 2008. Vol. 51, N 6. P. 5-12.

2. Sadovnikov M. A., Tomasov V. S., Tolmachev V. A. Precision electric drive of optical space control systems // Journal of Instrument Engineering. 2011. Vol. 54, N 6. P. 81-86.

3. Sinitsyn V. A., Tolmachev V. A., Tomasov V. S. Control systems of a positioning and tracking complex // Journal of Instrument Engineering. 1996. Vol. 39, N 6. P. 22-27.

4. Glazenko T. A., Tomasov V. S. Status and prospects of semiconductor converters implementation in instrument engineering // Journal of Instrument Engineering. 1996. Vol. 39, N 6. P. 5-10.

5. Mikheev K. E., Tomasov V. S. Analysis of energy performance of multilevel semiconductor converters of electric drive systems // Scientific and Technical Journal of Information Technologies, Mechanics and Optics. 2012. Vol. 12, N 1. P. 46-52.

6. Chintan Patel, Rajeevan P. P., Anubrata Dey, Rijil Ramchand, Gopakumar K., Kazmierkowski M. P. Fast direct torque control of an open-end induction motor drive using 12-sided polygonal voltage space vectors // IEEE Transact. on Power Electronics. 2012. Vol. 27, N 1. P. 400-410.

7. Mathew J., Mathew K., Azeez N. A., Gopakumar K. A hybrid multilevel inverter system based on dodecagonal space vectors for medium voltage IMdrives // IEEE Trans. Power Electronics. 2013. Vol. 28, N 8. P. 3723-3732.

8. Buja G. S., Kazmierkowski M. P. Direct torque control of PWM inverter-fed AC motors - A Survey // IEEE Transact. on Industrial Electronics. 2004. Vol. 51, iss. 4. P. 744-757.

9. Aleenejad M., Iman-Eini H., Farhangi S. A minimum loss switching method using space vector modulation for cascaded H-bridge multilevel inverter // Proc. of the XX Iranian Conf. on Electrical Engiineering Intern. 2012. P. 546-551.

10. Pinto J. O. P., Bose B. K., Silva L. E. B., Karmierkowski M. P. A neural network based space vector PWM controller for voltage-fed inverter induction motor drive // IEEE Transact. on Industry Applications. 1994. Vol. 36, N 6. P. $1628-1636$.

11. Neelima A. Neural network based space vector PWM control of induction motor // Intern. Journal of Engineering Research and Applications. 2012. Vol. 2, N 6. P. 104-116.

12. McGrath B. P., Holmes D. G., Lipo T. Optimized space vector switching sequences for multilevel inverters // IEEE Trans. Power Electronics. 2003. Vol. 18, N 6. P. 1293-1301.

13. Amol Shrikishan Thoratl, Ganesh D. Shingade, Avinash D. Matrel. Performance investigation of space vector pulse width modulated inverter fed induction motor drive // Proc. of the Intern. Conf. on Computation of Power, Energy, Information and Communication. 2014. P. 118-123.

14. Tomasov V. S., Usoltsev A. A. Comparative analysis of the energy efficiency of the scalar and space-vector PWM in a three-phase inverter // Russian Electrical Engineering. 2014. Vol. 85, N 2. P. 111-114.

15. Bowes S. R., Holliday D. Comparison of pulse-width-modulation control strategies for three-phase inverter systems // IEEE Proc. Electr. Power Appl. 2006. Vol. 153, N 4. P. 575-584.

16. Manoj Hirani, Sushma Gupta, Deshpande D. M. Comparison of performance of induction motor fed by sine pulse width modulated inverter and multi level inverter using XILINX // Proc. of the IEEE Intern. Conf. on Advanced Communication Control and Computing Technologies. 2014. P. 264-269.

17. Keliang Zhou, Danwei Wang. Relationship between space-vector modulation and three-phase carrier-based PWM: A Comprehensive Analysis // IEEE Transact. on Industrial Electronics. 2002. Vol. 49, N 1. P. 186-196. 
Valentin S. Tomasov _ - PhD, Associate Professor; ITMO University, Department of Electrotechnics and Precision Electromechanical Systems; E-mail: tomasov@ets.ifmo.ru

Aleksander A. Usoltsev - PhD, Associate Professor; ITMO University, Department of Electrotechnics and Precision Electromechanical Systems; E-mail: uaa@ets.ifmo.ru

Denis A. Vertegel _ - Student; ITMO University, Department of Electrotechnics and Precision Electromechanical Systems; E-mail: vertegeldenis@gmail.com

Ryszard Strzelecki — - Dr. Sci., PhD., Electrotechnical Institute, Warsaw; E-mail: profesor1958@gmail.com

Received 04.04.17

For citation: Tomasov V. S., Usoltsev A. A., Vertegel D. A., Strzelecki R. Space vector modulation in multilevel inverters of the servo drives of the trajectory measurements telescopes. Journal of Instrument Engineering. 2017. Vol. 60, N 7. P. 624-634 (in English).

\title{
ПРОСТРАНСТВЕННО-ВЕКТОРНАЯ МОДУЛЯЦИЯ \\ В МНОГОУРОВНЕВЫХ ИНВЕРТОРАХ СЕРВОПРИВОДОВ ТЕЛЕСКОПОВ ТРАЕКТОРНЫХ ИЗМЕРЕНИЙ
}

В. С. Томасов $^{1}$, А. А. Усольцев ${ }^{1}$, Д. А. Вертегел ${ }^{1}$, Р. Стжелецки ${ }^{2}$

${ }^{1}$ Университет ИТМО, 197101, Санкт-Петербург, Россия

E-mail: tomasov@ets.ifmo.ru

${ }^{2}$ Институт электротехники в Варшаве, Гдыня, Польша

\begin{abstract}
С использованием математической модели MatLab/Simulink трехфазного трехуровневого инвертора напряжения рассмотрено влияние алгоритма пространственно-векторной модуляции (ПВМ) на пульсации тока (момента) двигателя переменного тока в области низких скоростей вращения. Показано, что ПВМ второго рода не обеспечивает уровня пульсаций, сопоставимого с пульсациями при синусоидальной широтно-импульсной модуляции (СШИМ), как в статическом режиме работы привода, так и в переходных режимах. При этом пульсации тока не могут быть уменьшены путем изменения алгоритма модуляции, что практически исключает возможность применения таких преобразователей в высококачественных регулируемых приборных приводах переменного тока. В то же время ПВМ первого рода может рассматриваться как альтернатива СШИМ, так как позволяет уменьшить пульсации тока в большей части диапазона регулирования до сопоставимого уровня, а в последней четверти диапазона - до значений, существенно меньших, чем при СШИМ. Отмечена асимметрия характеристик инвертора с ПВМ при разных направлениях вращения вектора модуляции.
\end{abstract}

Ключевые слова: трехуровневый инвертор напряжения, пространственно-векторная модуляция, синусоидальная широтно-импульсная модуляция, алгоритм модуляции, пульсации тока, приборный электропривод

\section{Валентин Сергеевич Томасов}

Александр Анатольевич Усольцев

Денис Александрович Вертегел

Рышард Стжелецки

\section{Сведения об авторах}

- канд. техн. наук, доцент; Университет ИТМО, кафедра электротехники и прецизионных электромеханических систем; E-mail: tomasov@ets.ifmo.ru

- канд. техн. наук, доцент; Университет ИТМО, кафедра электротехники и прецизионных электромеханических систем; E-mail: uaa@ets.ifmo.ru

- студент; Университет ИТМО, кафредра электротехники и прецизионных электромеханических систем; E-mail: vertegeldenis@gmail.com

- д-р техн. наук, профессор; Институт электротехники, Варшава; E-mail: profesor1958@gmail.com

Ссылка для цитирования: Томасов В. С., Усольцев А. А., Вертегел Д. А., Стжелецки Р. Пространственно-векторная модуляция в многоуровневых инверторах сервоприводов телескопов траекторных измерений // Изв. вузов. Приборостроение. 2017. Т. 60, № 7. С. 624—634.

DOI: $10.17586 / 0021-3454-2017-60-7-624-634$ 